\title{
Review
}

\section{Exploiting Endocytosis for Non-Spherical Nanoparticle Cellular Uptake}

\author{
Saad Niaz, Ben Forbes (D) and Bahijja Tolulope Raimi-Abraham *(D) \\ School of Cancer and Pharmaceutical Sciences, King's College London, London SE1 9NH, UK; \\ saad.niaz@kcl.ac.uk (S.N.); ben.forbes@kcl.ac.uk (B.F.) \\ * Correspondence: Bahijja.Raimi-Abraham@kcl.ac.uk
}

check for updates

Citation: Niaz, S.; Forbes, B.; Raimi-Abraham, B.T. Exploiting Endocytosis for Non-Spherical Nanoparticle Cellular Uptake. Nanomanufacturing 2022, 2, 1-16. https://doi.org/10.3390/ nanomanufacturing2010001 Academic Editor: Mikhael Bechelany Received: 14 December 2021 Accepted: 27 January 2022 Published: 1 February 2022 Publisher's Note: MDPI stays neutral with regard to jurisdictional claims in published maps and institutional affiliations.

Copyright: (C) 2022 by the authors. Licensee MDPI, Basel, Switzerland. This article is an open access article distributed under the terms and conditions of the Creative Commons Attribution (CC BY) license (https:// creativecommons.org/licenses/by/ $4.0 /$ )

\begin{abstract}
Several challenges exist for successful nanoparticle cellular uptake-they must be able to cross many physical barriers to reach their target and overcome the cell membrane. A strategy to overcome this challenge is to exploit natural uptake mechanisms namely passive and endocytic (i.e., clathrin- and caveolin-dependent/-independent endocytosis, macropinocytosis and phagocytosis). The influence of nanoparticle material and size is well documented and understood compared to the influence of nanomaterial shape. Generally, nanoparticle shape is referred to as being either spherical or non-spherical and is known to be an important factor in many processes. Nanoparticle shape-dependent effects in areas such as immune response, cancer drug delivery, theranostics and overall implications for nanomedicines are of great interest. Studies have looked at the cellular uptake of spherical NPs, however, fewer in comparison have investigated the cellular uptake of non-spherical NPs. This review explores the exploitation of endocytic pathways for mainly inorganic non-spherical (shapes of focus include rod, triangular, star-shaped and nanospiked) nanoparticles cellular uptake. The role of mathematical modelling as predictive tools for non-spherical nanoparticle cellular uptake is also reviewed. Both quantitative structure-activity relationship (QSAR) and continuum membrane modelling have been used to gain greater insight into the cellular uptake of complex non-spherical NPs at a greater depth difficult to achieve using experimental methods.
\end{abstract}

Keywords: nanoparticle; endocytosis; cellular uptake; nanoparticle shape; spherical; non-spherical; cell membrane; continuum membrane modelling; quantitative structure-activity relationship modelling

\section{Introduction}

Nanoparticles (NPs), i.e., particles from 1 to $100 \mathrm{~nm}$ (though some are larger than $100 \mathrm{~nm}$ ) [1] can be engineered in a multitude of ways to give different sizes, shapes, and surface chemistries for a variety of applications ranging from energy production, industrial production processes, pharmaceutical and biomedical applications [2]. To be effective, nanomedicines (i.e., NPs used as therapeutic agents) must cross several cellular barriers and mechanisms as the route of entry into the cell to conduct their intended therapeutic function. The exploitable entry routes into the (eukaryotic) cell are by direct fusion with the plasma membrane [3], endocytosis [3], or passive diffusion [4]. Membrane fusion mechanisms occur when two lipid membranes combine to form one continuous bilayer resulting in lipid mixing and cellular content transfer [5]. This process is highly regulated involving several functional proteins such as soluble $N$-ethylmaleimide attachment protein receptor (SNARE) proteins and is a functional entry route for nanomedicines (e.g., content transfer via liposome-liposome fusion) [5]. Passive diffusion is a membrane transport mechanism that does not require energy for a substance to move across the membrane. The process occurs when the permeant partitions into the membrane, diffuses across and is then released into the cytosol [4].

Nevertheless, endocytosis remains the main route of entry of substances into the (eukaryotic) cell and can either be receptor (i.e., clathrin and caveolin), phagocytosis or macropinocytosis mediated [6,7]. 
The nature of the interaction between a nanomedicine and the outer membrane of cells is largely dependent on the material, size and shape of the nanostructure [8]. The influence of NP material and size is well documented and understood (see recent reviews [9-12]). The influence of nanomaterial shape is less documented in comparison. NP shape is referred to as being either spherical or non-spherical and is an essential design parameter for smart interactions with various targets [13]. NP shape is known to be an important factor in processes such as biodistribution [14] drug delivery and targeting [15], and cellular uptake $[13,16]$. NP shape-dependent effects in areas such as immune response [17], cancer drug delivery [18], theranostics [19] and overall implications for nanomedicine [20] are of great interest. The recent review by Kapate et al. 2021 provides a compressive review on the role (cell-particle interactions, particle transport, distribution and immune response) of non-spherical NPs in drug delivery and progress made in the last 15 years [21].

The specific objectives of this review are first, to explore the behaviours of (mainly inorganic) non-spherical NPs on specific endocytic cellular mechanisms namely clathrin and caveolin dependent and independent endocytosis, phagocytosis and macropinocytosis. Secondly, to discuss the specific effects of non-spherical NPs namely rod, triangular, starshaped and nanospiked on cellular uptake. Lastly, to highlight the role of predictive mathematical modelling such as quantitative structure-activity (QSAR) and continuum membrane modelling which have proven useful in investigating the influence of nonspherical NPs on cellular entry and uptake at a greater depth difficult to achieve using experimental methods $[22,23]$.

\section{Receptor-Mediated Nanoparticle Uptake}

Receptor-mediated endocytosis is a type of endocytosis whereby receptor proteins located on the surface of cells interact and bind with specific target molecules to elicit an endocytic response which involves the uptake of the target molecule into the cell via vesicle formation [6]. Ongoing developments in this field of research have identified five key types of receptor-mediated endocytosis: clathrin-dependent endocytosis, clathrin-independent endocytosis (of which there a two types-endophilin mediated/dynamin-dependent, and glycosylphosphatidylinositol-anchored protein-enriched (GEEC)), macropinocytosis, phagocytosis, and caveolin-dependent endocytosis [6]. Clathrin, caveolin, and dynamin are all proteins involved in receptor-mediated endocytosis. Clathrin is a protein involved in the formation of a polyhedral network on the cell membrane forming a coated pit as the membrane invaginates to form a vesicle during certain endocytic pathways [24]. Caveolin is another protein, of which there are three types (caveolin-1, caveolin-2, and caveolin-3), however, this protein specialises in the formation of caveolin-coated vesicles during endocytic pathways, with each type of caveolin being differentially expressed in different cell types [25]. Dynamin, unlike clathrin and caveolin, is a GTPase that plays a pivotal role in clathrin-independent endocytosis by acting as a molecular scissor to aid in the budding of vesicles from the cell membrane [26].

\subsection{Clathrin-Dependent Endocytosis}

Clathrin-dependent endocytosis (Figure 1) begins via the attachment of nanoparticle ligands to cell membrane receptors, e.g., epidermal growth factor (EGF) receptors. clathrindependent endocytosis involves many steps; the first being the formation of a pit coated with clathrin protein consisting of the receptor-bound NPs within the pit; this is followed by cell membrane invagination and the breaking-off of the cell membrane invagination to form an intracellular vesicle. The endocytosed NPs are then extracted from the vesicles where they can then reach their target. Clathrin-dependent endocytosis is capable of entrapping nanoparticles in intracellular vesicles approximately $100 \mathrm{~nm}$ in size [6,24]. These intracellular vesicles may then be transported to endosomes where the contents of the vesicle can undergo enzymatic degradation or engulfment $[27,28]$. Notably, clathrindependent endocytosis is instigated by the action of the adapter complex, AP2, which is involved in the recruitment of clathrin to form the coated pits [6]. Furthermore, this form of 
endocytosis also utilises dynamin which facilitates the scission of the vesicle from the cell membrane [6]. Clathrin-dependent endocytosis thus provides a viable cellular entry point for nanoparticles, which can be exploited for drug delivery. Benyettou et al. created silver NPs for the delivery of the anticancer drugs doxorubicin and alendronate to HeLa cancer cells [29]. The modified silver NPs, conjugated with doxorubicin and alendronate improved the anti-cancer activity of both drugs compared to when both drugs were administered on their own without the silver NP [29]. Figure 1 shows how clathrin-dependent endocytosis may be employed by NPs.

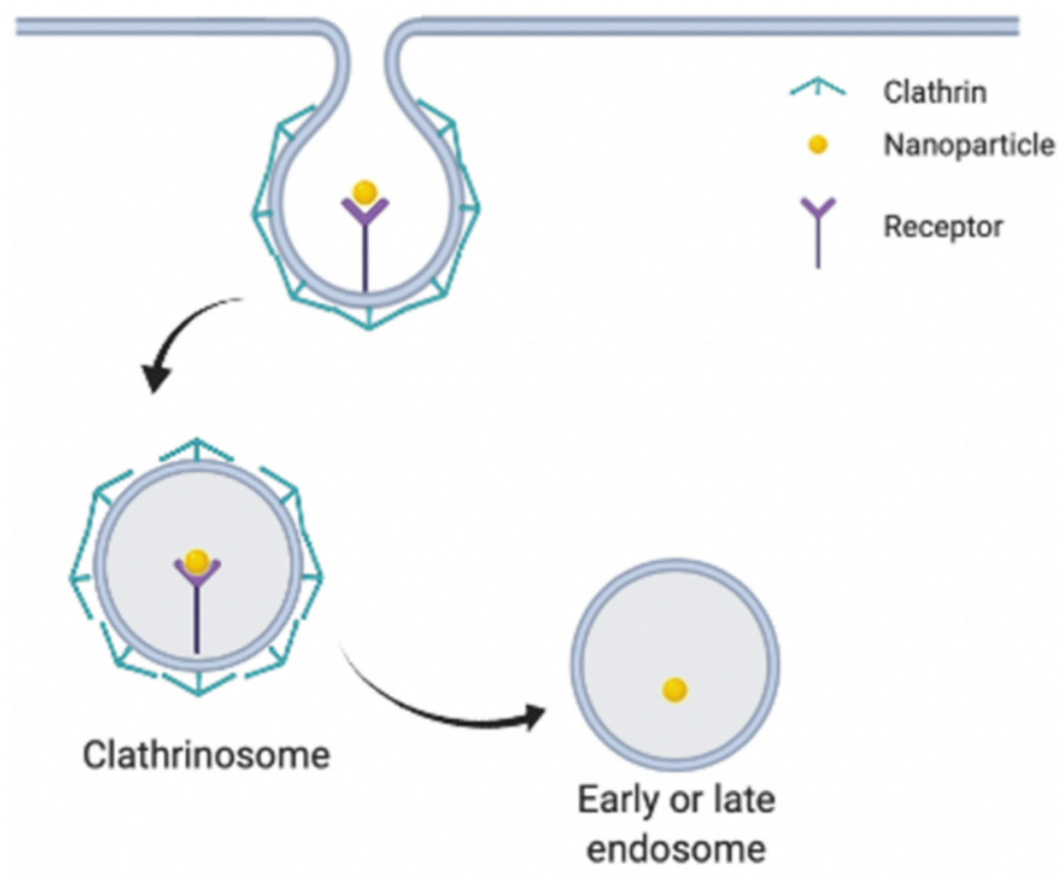

Figure 1. Clathrin dependent endocytosis. This figure shows how NPs employ clathrin-dependent endocytosis to gain entry into a cell. Adapted from [30].

\subsection{Caveolin-Dependent Endocytosis}

Caveolin-dependent endocytosis (Figure 2) also is receptor-mediated, and involves the binding of nanoparticles to a receptor, followed by flask-like membrane invaginations known as caveolae [31]. Each caveola is composed of the membrane protein caveolin which plays an integral role in forming the flask-like structure in caveolae. Caveolae then detach from the cell membrane forming the caveosome, which can evade any lysosomes, thus preventing degradation of NPs [32,33]. Caveolin-dependent endocytosis is mediated via the action of EH-domain containing protein 2 (EHD2) which stabilise the neck of caveolae [6]. Of the five types of receptor-mediated endocytosis pathways, caveolindependent endocytosis is utilised for the smallest amount of cargo, typically forming vesicles approximately $60 \mathrm{~nm}$ in diameter [6]. Typical destinations of NPs entering via this pathway include the Golgi apparatus and the endoplasmic reticulum [34]. Furthermore, recent studies have shown nanoparticles with folic acid, albumin or cholesterol surface ligands typically favour caveolin-dependent endocytosis [35]. Figure 2 summarises the process of caveolin-dependant endocytosis.

\subsection{Inhibitors of Clathrin- and Caveolin-Dependent Endocytosis}

Inhibitors are often used to study caveolin and clathrin-dependent endocytosis. Of particular interest are potential exploitable mechanisms that can be used by NPs to gain effective entry into the cell. [36]. Specific and non-specific chemical (pharmacological agents) inhibitors and genetic (genetically modified cells or organisms containing endocytic gene or protein knockouts) inhibitors are often used in studies to identify molecular components 
and processes as well as the physiological consequences of blocking specific endocytic pathways $[6,37]$.

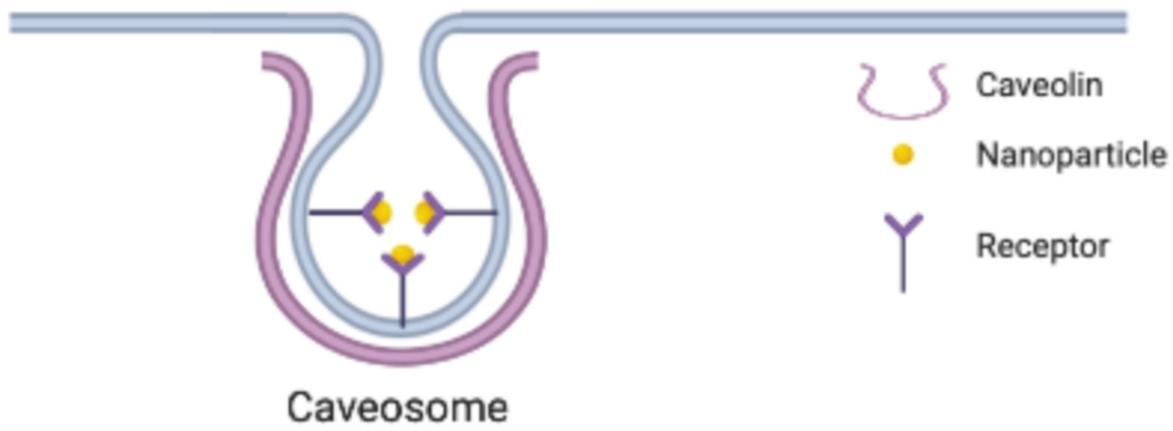

Figure 2. Caveolin-dependent endocytosis. This figure shows how NPs employ caveolin-dependent endocytosis to gain entry into a cell. Adapted from [30].

Specific and non-specific chemical inhibitors commonly used to investigate clathrindependent endocytosis include; hypertonic sucrose [38], potassium ion depletion [39], chlorpromazine [40], chloroquine [40], and pitstop 2 [6,41]. The mode of action of these inhibitors vary For example, hypertonic sucrose on-specifically traps clathrin in microcages and additionally interferes with elements of macropinocytosis [38]; potassium ion depletion causes clathrin aggregation [42]; whilst pitstop 2 interferes with binding to the $\mathrm{N}$-terminal domain of clathrin [41]. It has been suggested that known inhibitors of micropinocytosis and clathrin-independent endocytosis also inhibit fast endophilin-mediated endocytosis (FEME) [43].

Nystatin and methyl- $\beta$-cyclodextrin $(\mathrm{M} \beta \mathrm{CD})$ are non-specific chemical inhibitors of caveolin-dependent endocytosis [44,45]. Nystatin functions by binding to cholesterol, whilst $\mathrm{M} \beta \mathrm{CD}$ removes cholesterol from the plasma membrane; both inhibitors influence membrane fluidity and in turn cellular uptake $[6,45,46]$.

Genetic inhibitors are used to minimise non-specific inhibition often seen with chemical inhibitors and have shown great success. For example, the use of a genetic inhibitor to study clathrin-dependent endocytosis involves using a clathrin heavy chain (CLTC) gene knockout [47]. The CLTC gene encodes the clathrin heavy chain 1 protein which is a key component of clathrin that prevents the formation of clathrin-coated pits [47].

\subsection{Clathrin and Caveolin Independent Endocytosis}

Clathrin and caveolin independent endocytosis is a mechanism of endocytosis that does not utilise clathrin or caveolin proteins. Instead, they utilise lipid rafts (structures composed of cholesterol and sphingolipids) found within the cell membrane which is capable of being endocytosed [48]. Examples of this uptake route can be seen in the literature which identified lipid raft-mediated endocytosis mechanisms for modified NPs consisting of cell-penetrating peptides (CPPs) and nucleic acids [49,50]. More specifically, two types of clathrin-independent endocytosis have been identified: endophilin mediated/dynamindependent, and GEEC endocytosis [6]. Endophilin mediated/dynamin-dependent endocytosis is initiated via ligand-cell surface receptor interaction and is modulated by endophilin A2 recruitment and actin polymerization and, much like clathrin-dependent endocytosis, also requires dynamin protein [6]. GEEC endocytosis on the other hand is clathrin and dynamin independent and utilizes extracellular galectin proteins, glycoproteins, and glycolipids for vesicle formation and loading [6]. GEEC endocytic vesicles are capable of carrying cargo up to $100 \mathrm{~nm}$ in size, whilst vesicles formed during endophilin mediated/dynamin-dependent endocytosis pathway carry cargo approximately between 60-80 $\mathrm{nm}$ in size [6]. 


\subsection{Phagocytosis}

Phagocytosis (Figure 3) is a cellular uptake process carried out by cells of the immune system, such as macrophages, dendritic cells, neutrophils, and B lymphocytes. The function of phagocytosis is to remove pathogens, diseased cells, and other biological debris which are unknown to the body [51]. Phagocytosis of NPs can be instigated via interaction with phagocyte cells surface receptors, such as Fc receptors and complement receptors. Phagocytes (cells that specifically perform phagocytosis) regularly identify and can remove NPs from circulation [52]. Phagocytosis can be used in the cellular uptake of larger cargo typically greater than $200 \mathrm{~nm}$ in size and could thus allow for uptake of larger NPs [6]. Components of the immune system such as immunoglobulins and complement proteins are responsible for the identification and removal of NPs by phagocytes through opsonization and adsorption onto the nanoparticle surface. When NPs are phagocytosed, they are contained within phagosome vesicles which in turn fuse with a lysosome, thus forming the phagolysosome. Phagocytosis poses a difficult challenge for the development of nanomedicines due to the action of phagolysosomes which can cause the enzymatic breakdown of foreign materials, including NPs [53].

When NPs are administered intravenously they are immediately opsonized (the process of immunologically tagging pathogens for phagocytosis) upon contact with blood [54,55]. Opsonized NPs often are sequestered by macrophages [56]. NP surface modifications have been introduced to reduce NP sequestration by macrophages and phagocytic cells, by reducing opsonization [57]. One approach has been to coat the surface of NPs using poly(ethylene glycol) (PEG) [58]. The surface density and degree of polymerization of PEG influences the opsonization of NPs [59]. However, the drawback of using PEG is its potential immunogenicity, since repeated administration of PEGylated NPs can result in the production of PEG-specific antibodies which facilitate the removal of the NPs [60,61].

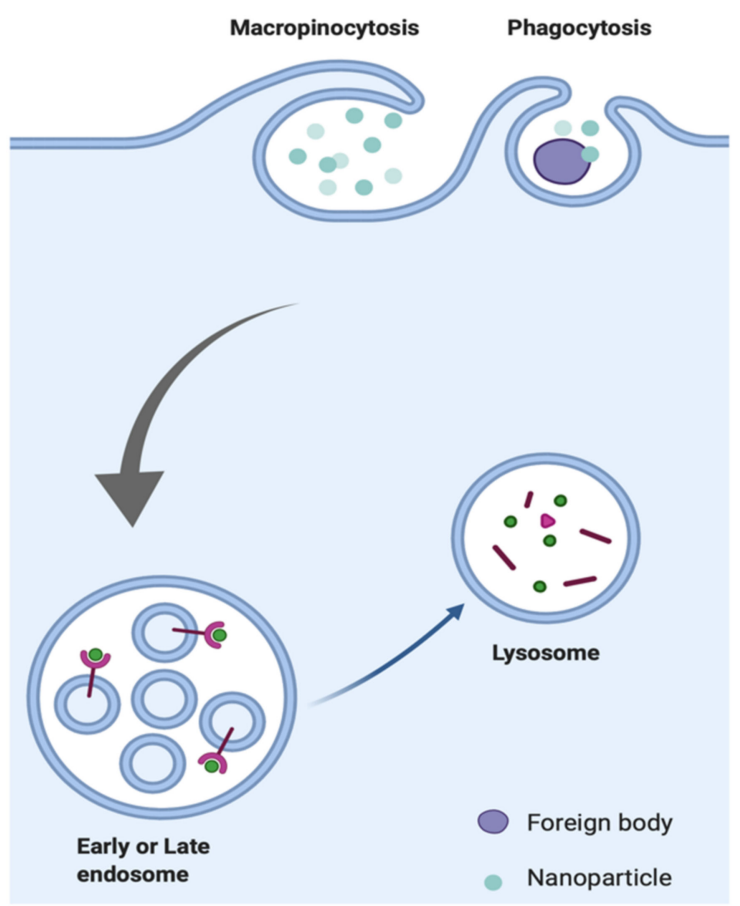

Figure 3. Macropinocytosis and phagocytosis. This figure shows how NPs employ phagocytosis and macropinocytosis to gain entry into a cell. The early or late endosome shows vesicles consisting of receptor-bound NPs encapsulated within an endosome. The lysosome shows the presence of debris as a result of the degradation of vesicles consisting of receptor-bound nanoparticles. Adapted from $[53,62]$. 


\subsection{Macropinocytosis}

Macropinocytosis (Figure 3) is a non-specific cellular uptake mechanism involving the engulfment of extracellular fluids via extensions of the cell membrane which are structurally supported by actin protein [62]. Unlike other endocytic pathways, actin signalling plays a major role in the process of micropinocytosis and is what initiates it $[63,64]$. The process of micropinocytosis results in the creation of macropinosomes (approximately 0.5 to $1.5 \mu \mathrm{m}$ in diameter) which are capable of entrapping NPs and other ingested material, and are capable of uptake of cargo greater than $200 \mathrm{~nm}$ in diameter [6,65-67].

\section{Non-Spherical Nanoparticle Specific Considerations on Cellular Uptake}

Non-spherical nanoparticles have both shape and size-dependent behaviours. In addition to the influence of NP shape on cellular uptake, NP shape also plays an important role in the cell adhesion process which is one of the first stages in many endocytic pathways [68]. NP wrapping is the first process in cellular uptake and occurs as a result of NP-cell membrane interactions which generates different forces greatly influenced by nanoparticle size, shape, stiffness and local cell environment [69]. Spherical and non-spherical NPs require different wrapping energies for cellular uptake [23]. Non-spherical NPs can exhibit high wrapping fractions (i.e., the ratio of the particle wrapped by the membrane) and the orientation can influence the wrapping rate and surface energy required [70]. Additionally, altering the NP shape alters the aspect ratio of NPs which has been shown to influence the uptake of NPs, as different aspect ratios provide different orientation possibilities to allow for interaction with cells [71].

\subsection{Rod-Shaped Nanoparticles}

Rod-shaped NPs are NPs that have a cylindrical/capsule-like appearance with dimensions within the NP range of 1-100 nm [2]. Of particular interest, altering the aspect ratio has been shown to influence the uptake of rod-shaped NPs [72,73]. High aspect ratios common with non-spherical NPs coupled with size differences can additionally result in different cell line-specific internalization pathways $[23,74]$.

There is still debate on which NP shape, i.e., spherical or non-spherical offers better cellular entry and uptake [75-77]. NP shape can influence the accumulation and biodistribution within cells and tissues [71,78]. Work by Arnida et al., saw a greater accumulation of $50 \mathrm{~nm}$ spherical gold NPs in prostate cancer cells compared to gold nanorods with dimensions in the range of 30-90 nm [79]. Work by Zhang et al., found that cellular uptake of cationised gold nanorods into HepG2 cells was 1.5 times greater compared to their spherical counterpart [80]. A proposed theory as to why rod-shaped NPs show greater cellular uptake is thought to be due to their orientation on cell membrane contact, i.e., if the nanorod tip (Figure 4) makes initial contact with the cell membrane, this aids favourable uptake due to low surface energy requirements in cell membrane wrapping [80]. Another proposed explanation is due to the higher surface area of nanorods compared to spherical NPs resulting in multiple interactions with the cell surface which facilitate uptake, whereas spherical particles make fewer contacts with the cell surface due to the smaller surface area at the point of contact with the cell membrane [81-83].

\subsection{Triangular Nanoparticles}

Triangular NPs similar to rod-shaped NPs have unique aspect ratios and surface to volume ratios that are capable of eliciting different cellular internalization pathways [84]. Triangular NPs in particular have been commonly used for their antimicrobial activity as they have been proven to be the most effective shape for antimicrobial activity owing to the sharp vertex and edges enabling the NPs to penetrate and cause damage to the cell membrane more easily [84]. 


\section{Proposed method of cellular entry for rod-shaped NPs}

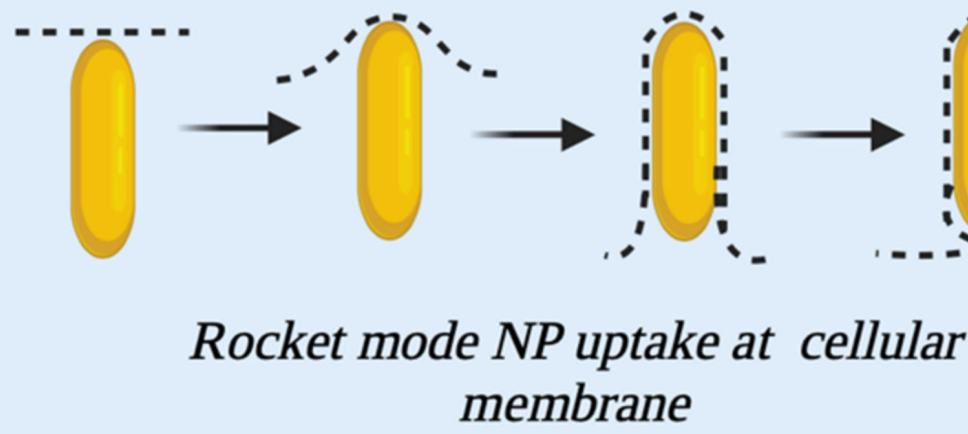

Figure 4. The proposed method of cellular entry for rod-shaped NPs. This figure highlights membrane wrapping that occurs during cellular entry of rod-shaped NPs via rocket mode uptake at the cell membrane. (Adapted from [23]).

Nambara and co-workers examined the uptake capabilities of four different sized triangular NPs (TNPs) - with side lengths of 46, 55, 72, $94 \mathrm{~nm}$ and a thickness of $30 \mathrm{~nm}$. The cellular internalisation efficiency of the TNPs was compared to spherical nanoparticles of diameters 22, 39 and $66 \mathrm{~nm}$. Inductively coupled plasma emission spectrometry (ICP-ES) data showed that TNPs with longer side lengths had greater levels of uptake in RAW264.7 and HeLa cells [85]. RAW264.7 cells are mouse leukaemic macrophages and much like HeLa cells and breast cancer cells can also be used as a cell model to study cellular uptake of NPs [36,86-89]. Furthermore, in HeLa cells, in particular, there was a 20-fold more efficient internalisation observed for TNPs with longer sides $(72 \mathrm{~nm})$ compared to spherical nanoparticles $(66 \mathrm{~nm})$ with a smaller surface area [85]. In another study, the cellular uptake of gold nanoparticles (coated with methylpolyethyen glycol) in the form of stars, rods and triangles was compared in RAW264.7 cells. The study found that triangular nanoparticles showed the greatest levels of uptake in the RAW264.7 cells, followed by rod-shaped nanoparticles and then star-shaped nanoparticles [36]. Additionally, to examine which endocytic pathways were at play, Xie et al. used various endocytic inhibitors to evaluate the involvement of different endocytic pathways in the uptake of the three different shaped NPs. For example, to investigate clathrin-dependent endocytosis, RAW264.7 cells were treated with sucrose (a clathrin-dependent endocytosis inhibitor) and found the uptake of all three types of NP were reduced, indicating that star, rod and triangular gold NPs utilised clathrin-mediated endocytosis [36]. In the same study, methyl-beta-cyclodextrin $(\mathrm{M} B C D)$ was used as a caveolae/lipid-raft inhibitor, strong inhibition was observed only for the rod-shaped gold NPs, indicating rod-shaped NPs favoured caveolin dependent endocytosis [36].

\subsection{Star-Shaped Nanoparticles}

Star-shaped nanoparticles (also referred to as "nanostars") are another type of nanoparticle which are commonly studied. Nanostars have several valuable properties; their larger surface area to volume ratio and interaction cross-section compared to spherical NPs 
means that they can be used for catalytic applications because of their large surface area which improves their reactivity [90]. Furthermore, the large interaction cross-section of nanostars can make them valuable for radiation therapy as they provide a radiation dose improvement [90].

Yue et al., examined the potential ability of spherical and star-shaped gold NPs as drug carriers by comparing their efficiency of cellular uptake to spherical NPs in U87 glioblastoma cells, when treated with small interfering RNAs (siRNAs) [91]. Inductively coupled mass spectrometry (ICP-MS) was used to quantify the uptake of the siRNA treated gold spherical and star-shaped NPS. Interestingly, the cellular uptake of spherical NPs increased at a greater rate compared to the nanostars and uptake efficiency was almost 1.6 times greater than that of the nanostars, showing that star-shaped NPs may not be as efficient as spherical NPs in carrying siRNAs [91]. Greater uptake of the spherical siRNA treated gold NPs could have been due to the differences in interactions between the oligonucleotides presented by the spherical and star-shaped NPs with cell membrane class A scavenger receptors which are implicated in the uptake of oligonucleotide treated spherical NPs [92]. When NPs enter a cell or biological system, they become coated in various proteins to form the protein corona, thus, if star-shaped NPs entered a cell, their uptake could directly be affected by the interactions of their protein corona with the cell membrane receptors. In a similar way to the oligonucleotide/siRNA gold star NPs, other types of star-shaped NPs could have reduced cellular uptake efficiencies compared to other shaped NPs [36,93].

\subsection{Nanospiked Microparticles}

Nanospiked particles are a form of NP consisting of a spherical base structure with spike-like protrusions coming from the surface of the particle. Similar to nanostars, nanospikes also have a high surface area to volume ratio which improves reactivity and have a high interaction cross surface making this shape valuable for radiation therapy applications $[90,94]$. As a result, of these features their cellular uptake is also influenced by $\mathrm{Ma}$ and co-workers identifying cellular uptake of spherical gold NPs, gold nanospikes and gold nanorods to have uptake efficiencies in human oral epidermoid carcinoma (KB) cells in the following order: spherical gold NPs > gold nanospikes > gold nanorods [94].

One particular study, by Wang et al. reported that nanofeatures such as nanospikes are capable of eliciting an innate immune response [95]. In this study, $\mathrm{TiO}_{2}$ microparticles were modified to have "nanospikes" on their surface which initiated innate immune responses during phagocytosis [95]. More specifically, the nanospiked microparticles were responsible for activating dendritic cell maturation and inflammasomes (receptors of the innate immune system), however, microparticles without nanospikes did not cause any activation [95]. The promising immune-boosting effects of nanospiked particles could prove to be highly effective for the development of cancer immunotherapies due to their ability to induce immune system responses. These findings highlight how careful and considered approaches to material design could be used as a tool for developing more effective immunotherapies and vaccines of the future.

\subsection{Non-Spherical Nanoparticle Surface Charge Effects on Cellular Uptake}

NP surface charge(positive or negative) is an important property that can influence their cellular uptake as a result of the different ionic interactions possible with cell membrane which is negatively charged [96]. A study investigating morphology and surface charge-dependent cellular uptake of upconversion NPs (UCNPs) (NPs that exhibit photon upconversion) found that a higher surface charge coupled with a larger NP surface-tovolume ratio resulting in more efficient cellular uptake. [97] Additionally, positively charged UCNPs will low surface-to-volume ratios such as rod-shaped NPs resulted in lower uptake efficiency compared to hexagonal NPs [97]. In addition to shape influences on surface charge effects on cellular uptake, NP size is of equal importance and should be considered in NP design. However, it should be noted that cell line dependent differences may be ob- 
served and the impact as it relates to the therapeutic efficacy of NP in vivo biodistribution should also be explored [98,99].

\section{Modelling Cellular Uptake of Nanoparticles}

Biomedical applications of NPs are largely dependent on their ability to be taken up into cells. Experimental determination of cellular uptake of different nanoparticles in different cell types can be tedious, expensive and time-intensive, thus alternative methods are required. One such approach has been to use various mathematical modelling techniques. One of the major advantages of using mathematical modelling techniques to predict the uptake of non-spherical NPs is that it allows one to test the uptake of certain shapes which may be more difficult to produce experimentally, e.g., nanospikes, thus modelling provides an alternative route to examine the uptake of non-spherical NPs. Additionally, the use of modelling techniques allows one to control the variables being investigated more stringently and investigate only the variables of interest-for example, using wet-lab approaches to investigate non-spherical NP uptake would be more prone to being affected by other properties which affect NP uptake, e.g., pH. Furthermore, as the potential advantages of non-spherical NPs for cell uptake become more apparent, there is an increasing need to be able to model the uptake interactions of non-spherical NPs to give greater insight into mechanisms that these NPs employ to enter the cell. Two methods of modelling cellular uptake of NPs include quantitative structure-activity relationship (QSAR) modelling and continuum membrane modelling. The main advantage of QSAR modelling is that it can consider surface ligands present on functionalised NPs as well NP binding affinity based on NP shape. QSAR modelling does not however consider the influence of cell membrane surface energies that influence NP cellular uptake-for this, the continuum membrane model has been utilised.

\subsection{Quantitative Structure-Activity Relationship (QSAR) Model}

One such model which has previously been used to model cellular uptake has been the quantitative structure-activity (QSAR) model. Quantitative structure-activity relationship (QSAR) approaches to determine the physicochemical properties based on the molecular structures of a variety of compounds. These ligand-based computational screening methods offer a great alternative to the cost and labour-intensive screening wet-lab experiments [22]. The basic steps of developing a QSAR model involve (i) generation/curation of a large library to be used in the model building process (ii) calculation and selection of molecular descriptors. Molecular descriptors can be structural or physiochemical properties of a molecule or part of a molecule. (iii) Predictive modelling using ensemble learning approaches such as Decision TreeBoost (DTB) or Decision Tree Forest (DTF) approaches. DTB and DTF are essentially two separate systems that can be used to create a predictive decision tree, which is essentially a graph that uses a branching method to illustrate every possible outcome of a decision [100]. One particular study by Basant and co-workers used QSAR modelling with DTB to predict the uptake of functionalised NPs in six different cell linesPaCa2, HUVEC, RestMph, GMCSF_Mph and U937 [101]. The molecular descriptors used to predict uptake of functionalised NPs in different cell lines included their hydrophobicity, lipophilicity, hydrogen bonding ability, polarizability, molecular topological complexity and presence of heteroatoms, these characteristics are some of the most important characteristics determining the uptake of a nanoparticle in a cell and are important in facilitating surface interactions, protein binding affinity and cell permeability [102-104]. The study found that functionalised NPs that exhibited hydrophobicity and lipophilicity showed a positive correlation with cellular uptake in U937 and HUVEC cell lines [101].

\subsection{Continuum Membrane Model}

Other approaches to modelling cellular uptake of NPs have involved using the continuum membrane model. This form of modelling looks at the mechanical characteristics of the membrane, such as membrane elasticity, as opposed to the chemical characteristics 
as in QSAR modelling. This form of modelling is based on the curvature energy of lipid membranes combined with the contact adhesion energy for the interaction between the particle surface and the membrane [105]. The total membrane curvature energy takes into account the entire membrane area, the adhered membrane area (i.e., the area where the particle surface comes into contact with the membrane), the mean membrane curvature, the bending rigidity, the membrane tension and the adhesion strength for the interaction between the membrane and NP [23]. Dasgupta et al., utilised the continuum membrane model to determine the modes of entry for NP uptake by membrane wrapping of different shaped NPs. It was found that rod-shaped NPs favoured entry into the cell via submarine mode whereby the NP would first make contact using the elongated side of the NP as opposed to the tip [23]. Furthermore, they found that rod-like NPs because of the flat parts of their surface were able to adhere to the membrane even with very low adhesion strengths, unlike the spherical and ellipsoidal NPs [23].

\subsection{Molecular Dynamic Simulations}

Molecular dynamic (MD) simulations have been used to investigate molecular behaviours during receptor-mediated membrane wrapping processes for NPs [106]. MD simulations use numerical methods to probe the complexities of biomolecular systems [107]. Coarse-grain (CG) lipid models can be used to simulate the cell membrane by identifying specific types of lipid and grouping them according to a certain set of top-down (i.e., thermodynamic based) or bottom-up (i.e., structure-based) parameters [108].

The Martini model is a widely applied CG model for biomembranes that utilises both top-down and bottom-up parameterisation strategies [108]. In addition to lipids, the Martini model has been used to simulate proteins [109], carbohydrates [110], nucleotides [111], polymers [112], and NPs [113,114]. An in silico study using coarse-grain MD simulations to investigate the influence of size, shape surface charge and aggregation of gold NPs on cellular uptake, found that gold nanohexapods resulted in the highest rates of cellular uptake [114]. This was compared to their nanosphere, nanorod, nanoplate, and nanocage counterparts [114]. The authors concluded that the size and surface properties of spherical gold NPs influenced their rate of uptake far greater than other shapes of NP [114].

Dissipative particle dynamics (DPD) (a type of CG modelling) focuses primarily on simulating the hydrodynamic behaviours and has also been used to model the uptake of non-spherical NPs [115]. [116,117]. For example, to investigate the effect of NP shape on translocation across lipid membranes, with rod-shaped NPs appearing to be the most efficient followed by disc-shaped NPs and then spherical NPs [117].

All-atom (AA) models are also used to model lipid membrane interactions and have been shown to provide greater accuracy compared to CG models [118]. AA models are constructed based on atomic composition and bonding information between atoms [118]. Therefore, simulations via these models can prove useful for observing detailed interactions between the NP and cell membrane [119].

These studies highlight the value of modelling NP cellular uptake. The use of models or simulations can provide important predictive information that can result in improved design of NPs and nanomedicines. Table 1 summarises the common modelling strategies employed to simulate and investigate NP ceullar uptake. 
Table 1. Summary of modelling strategies to simulate NP cellular uptake.

\begin{tabular}{|c|c|c|c|}
\hline Model & Model Type & Description & Reference \\
\hline $\begin{array}{l}\text { Quantitative structure } \\
\text { relationship (QSAR) model }\end{array}$ & QSAR & $\begin{array}{l}\text { Ligand-based computational screening } \\
\text { method. Utilises a decision tree method } \\
\text { consisting of molecular descriptors for } \\
\text { structural or physiochemical properties } \\
\text { of molecules. }\end{array}$ & {$[22,101-104]$} \\
\hline Continuum membrane model & Molecular dynamic & $\begin{array}{c}\text { A form of molecular dynamics modelling } \\
\text { based on the curvature energy of lipid } \\
\text { membranes combined with the contact } \\
\text { adhesion energy for the interaction } \\
\text { between the particle surface and the } \\
\text { membrane. }\end{array}$ & {$[23]$} \\
\hline Martini model & Coarse-grain model (CG) & $\begin{array}{l}\text { It is an example of a CG model which } \\
\text { utilises both top-down and bottom-up } \\
\text { parameterisation strategies. This model is } \\
\text { capable of simulating proteins, } \\
\text { carbohydrates, nucleotides, polymers, } \\
\text { and NPs. }\end{array}$ & [109-114] \\
\hline $\begin{array}{l}\text { Dissipative particle dynamics } \\
\text { (DPD) }\end{array}$ & Coarse-grain model (CG) & $\begin{array}{l}\text { A form of CG model used to simulate } \\
\text { hydrodynamic behaviours of complex } \\
\text { fluids. }\end{array}$ & [115-117] \\
\hline All-atom (AA) model) & Molecular dynamic & $\begin{array}{l}\text { These models are constructed based on } \\
\text { atomic composition and bonding } \\
\text { information between atoms. They } \\
\text { provide greater accuracy but are limited } \\
\text { in the biological processes they can } \\
\text { model. }\end{array}$ & {$[118,119]$} \\
\hline
\end{tabular}

\section{Conclusions}

This review explored the behaviours of non-spherical NPs namely rod, triangular, star-shaped and nanospiked as they related to specific endocytic cellular uptake mechanisms. Here, the review also highlights the role of predictive mathematical modelling tools, quantitative structure-activity (QSAR) and continuum membrane modelling to predict non-spherical NPs cellular entry and uptake. NP shape plays a role in cellular uptake however, additional considerations such as NP charge and surface ligands also play a role. The cell membrane environment such as alterations in surrounding $\mathrm{pH}$ can change the interfacial tension which can result in a reduced ability of the cell membrane to initiate uptake mechanisms such as endocytosis [120,121]. Additional membrane composition and structural considerations include the glycocalyx coating which is of importance in the endothelium. The glycocalyx coating has a porous structure and studies have found that degradation of this coating can reduce the cellular entry of PEG-AuNPs due to disruption of the glycocalyx pore size [121]. Predictive mathematic modelling tools can be utilised to further understand cellular uptake for a larger range of non-spherical NPs that may prove difficult to determine experimentally. With the growing evidence highlighting the advantages as it relates to cellular uptake of non-spherical NPs, this should incentivise further work in this area.

Overall, knowledge of NP shape interaction with the cell membrane can be exploited to develop more effective nanomedicines capable of reaching their cellular targets, therefore minimising non-specific cellular interaction. A greater understanding of the uptake pathways available for NP exploitation will help guide the design of future nanomedicines capable of providing new and innovative medical solutions and solving unmet clinical needs. 


\begin{abstract}
Author Contributions: S.N.: Conceptualization, Investigation, Writing-Original Draft, WritingReview and Editing. B.F.: Conceptualization, Supervision, Project administration. B.T.R.-A.: Conceptualization, Writing-Review and Editing, Supervision, Project administration. All authors have read and agreed to the published version of the manuscript.

Funding: This work was supported by the BBSRC and London interdisciplinary Doctoral (LiDo) training programme.
\end{abstract}

Acknowledgments: We would like to thank the BBSRC and the London Interdisciplinary Doctoral (LiDo) programme for providing funding during this project. Figures were created with BioRender. com (accessed on 13 December 2021).

Conflicts of Interest: The authors declare no conflict of interest.

\title{
References
}

1. Bahadar, H.; Maqbool, F.; Niaz, K.; Abdollahi, M. Toxicity of Nanoparticles and an Overview of Current Experimental Models. Iran. Biomed. J. 2016, 20,1-11. [PubMed]

2. Jeevanandam, J.; Barhoum, A.; Chan, Y.S.; Dufresne, A.; Danquah, M.K. Review on nanoparticles and nanostructured materials: History, sources, toxicity and regulations. Beilstein J. Nanotechnol. 2018, 9, 1050-1074. [CrossRef] [PubMed]

3. Sigismund, S.; Confalonieri, S.; Ciliberto, A.; Polo, S.; Scita, G.; Di Fiore, P.P. Endocytosis and signaling: Cell logistics shape the eukaryotic cell plan. Physiol. Rev. 2012, 92, 273-366. [CrossRef]

4. Yang, N.J.; Hinner, M.J. Getting Across the Cell Membrane: An Overview for Small Molecules, Peptides, and Proteins. In Site-Specific Protein Labeling: Methods and Protocols; Gautier, A., Hinner, M.J., Eds.; Springer: New York, NY, USA, 2015; Volume 1266, pp. 29-53.

5. Yang, J.; Bahreman, A.; Daudey, G.; Bussmann, J.; Olsthoorn, R.C.L.; Kros, A. Drug Delivery via Cell Membrane Fusion Using Lipopeptide Modified Liposomes. ACS Cent. Sci. 2016, 2, 621-630. [CrossRef] [PubMed]

6. Rennick, J.J.; Johnston, A.P.R.; Parton, R.G. Key principles and methods for studying the endocytosis of biological and nanoparticle therapeutics. Nat. Nanotechnol. 2021, 16, 266-276. [CrossRef]

7. Manzanares, D.; Ceña, V. Endocytosis: The Nanoparticle and Submicron Nanocompounds Gateway into the Cell. Pharmaceutics 2020, 12, 371. [CrossRef]

8. Watson, H. Biological membranes. Essays Biochem. 2015, 59, 43-69. [CrossRef]

9. Dolai, J.; Mandal, K.; Jana, N.R. Nanoparticle Size Effects in Biomedical Applications. ACS Appl. Nano Mater. 2021, 4, 6471-6496. [CrossRef]

10. Hoshyar, N.; Gray, S.; Han, H.; Bao, G. The effect of nanoparticle size on in vivo pharmacokinetics and cellular interaction. Nanomedicine 2016, 11, 673-692. [CrossRef]

11. Modena, M.M.; Rühle, B.; Burg, T.P.; Wuttke, S. Nanoparticle Characterization: What to Measure? Adv. Mater. 2019, 31, 1901556. [CrossRef]

12. Khan, I.; Saeed, K.; Khan, I. Nanoparticles: Properties, Applications and Toxicities. Arab. J. Chem. 2019, 12, 908-931. [CrossRef]

13. Zhu, X.; Vo, C.; Taylor, M.; Smith, B.R. Non-Spherical Micro-and Nanoparticles in Nanomedicine. Mater. Horiz. 2019, 6, 1094-1121. [CrossRef]

14. Talamini, L.; Violatto, M.B.; Cai, Q.; Monopoli, M.P.; Kantner, K.; Krpetić, Ž.; Perez-Potti, A.; Cookman, J.; Garry, D.; Silveira, C.P.; et al. Influence of Size and Shape on the Anatomical Distribution of Endotoxin-Free Gold Nanoparticles. ACS Nano. 2017, 11, 5519-5529. [CrossRef]

15. Haryadi, B.M.; Hafner, D.; Amin, I.; Schubel, R.; Jordan, R.; Winter, G.; Engert, J. Nonspherical Nanoparticle Shape Stability Is Affected by Complex Manufacturing Aspects: Its Implications for Drug Delivery and Targeting. Adv. Health Mater. 2019, 8, e1900352. [CrossRef]

16. Zhang, J.; Xu, B.; Tian, W.; Xie, Z. Tailoring the morphology of AIEgen fluorescent nanoparticles for optimal cellular uptake and imaging efficacy. Chem. Sci. 2018, 9, 2620-2627. [CrossRef]

17. Kumar, S.; Anselmo, A.; Banerjee, A.; Zakrewsky, M.; Mitragotri, S. Shape and size-dependent immune response to antigencarrying nanoparticles. J. Control. Release 2015, 220, 141-148. [CrossRef]

18. Truong, N.; Whittaker, M.; Mak, C.W.; Davis, T.P. The importance of nanoparticle shape in cancer drug delivery. Expert Opin. Drug Deliv. 2014, 12, 129-142. [CrossRef]

19. Perry, J.L.; Herlihy, K.P.; Napier, M.E.; DeSimone, J.M. PRINT: A Novel Platform Toward Shape and Size Specific Nanoparticle Theranostics. Acc. Chem. Res. 2011, 44, 990-998. [CrossRef]

20. Kinnear, C.; Moore, T.L.; Rodriguez-Lorenzo, L.; Rothen-Rutishauser, B.; Petri-Fink, A. Form Follows Function: Nanoparticle Shape and Its Implications for Nanomedicine. Chem. Rev. 2017, 117, 11476-11521. [CrossRef]

21. Kapate, N.; Clegg, J.R.; Mitragotri, S. Non-spherical micro- and nanoparticles for drug delivery: Progress over 15 years. Adv. Drug Deliv. Rev. 2021, 177, 113807. [CrossRef] 
22. Cherkasov, A.; Muratov, E.N.; Fourches, D.; Varnek, A.; Baskin, I.I.; Cronin, M.; Dearden, J.; Gramatica, P.; Martin, Y.C.; Todeschini, R.; et al. QSAR Modeling: Where Have You Been? Where Are You Going To? J. Med. Chem. 2014, 12, 4977-5010. [CrossRef]

23. Dasgupta, S.; Auth, T.; Gompper, G. Shape and Orientation Matter for the Cellular Uptake of Nonspherical Particles. Nano. Lett. 2014, 14, 687-693. [CrossRef]

24. Kaksonen, M.; Roux, A. Mechanisms of clathrin-mediated endocytosis. Nat. Rev. Mol. Cell Biol. 2018, 19, 313-326. [CrossRef]

25. Williams, T.M.; Lisanti, M.P. The caveolin proteins. Genome Biol. 2004, 5, 214. [CrossRef]

26. Sundborger, A.; Hinshaw, J.E. Regulating dynamin dynamics during endocytosis. F1000Prime Rep. 2014, 6, 85. [CrossRef]

27. Decuzzi, P.; Ferrari, M. The Receptor-Mediated Endocytosis of Nonspherical Particles. Biophys. J. 2008, 94, 3790-3797. [CrossRef]

28. Robertson, A.S.; Smythe, E.; Ayscough, K.R. Functions of actin in endocytosis. Experientia 2009, 66, 2049-2065. [CrossRef] [PubMed]

29. Benyettou, F.; Rezgui, R.; Ravaux, F.; Jaber, T.; Blumer, K.; Jouiad, M.; Motte, L.; Olsen, J.-C.; Platas-Iglesias, C.; Magzoub, M.; et al. Synthesis of silver nanoparticles for the dual delivery of doxorubicin and alendronate to cancer cells. J. Mater. Chem. B 2015, 3, 7237-7245. [CrossRef] [PubMed]

30. Donahue, N.D.; Acar, H.; Wilhelm, S. Concepts of nanoparticle cellular uptake, intracellular trafficking, and kinetics in nanomedicine. Adv. Drug Deliv. Rev. 2019, 143, 68-96. [CrossRef] [PubMed]

31. Wang, Z.; Tiruppathi, C.; Cho, J.; Minshall, R.D.; Malik, A.B. Delivery of nanoparticle-complexed drugs across the vascular endothelial barrier via caveolae. IUBMB Life 2011, 63, 659-667. [CrossRef]

32. Kirkham, M.; Fujita, A.; Chadda, R.; Nixon, S.; Kurzchalia, T.V.; Sharma, D.K.; Pagano, R.E.; Hancock, J.; Mayor, S.; Parton, R.G Ultrastructural identification of uncoated caveolin-independent early endocytic vehicles. J. Cell Biol. 2005, 168, 465-476. [CrossRef]

33. Foroozandeh, P.; Aziz, A.A. Insight into Cellular Uptake, and Intracellular Trafficking of Nanoparticles. Nanoscale Res. Lett. 2018, 13, 339. [CrossRef]

34. Yameen, B.; Choi, W.I.; Vilos, C.; Swami, A.; Shi, J.; Farokhzad, O.C. Insight into Nanoparticle Cellular Uptake and In-tracellular Targeting. J. Control. Release 2014, 190, 485-499. [CrossRef]

35. Blanco, E.; Shen, H.; Ferrari, M. Principles of nanoparticle design for overcoming biological barriers to drug delivery. Nat. Biotechnol. 2015, 33, 941-951. [CrossRef]

36. Xie, X.; Liao, J.; Shao, X.; Li, Q.; Lin, Y. The Effect of shape on Cellular Uptake of Gold Nanoparticles in the forms of Stars, Rods, and Triangles. Sci. Rep. 2017, 7, 1-9. [CrossRef]

37. Dutta, D.; Donaldson, J.G. Search for inhibitors of endocytosis: Intended specificity and unintended consequences. Cell Logist. 2012, 2, 203-208. [CrossRef]

38. Hansen, S.; Sandvig, K.; Van Deurs, B. Molecules internalized by clathrin-independent endocytosis are delivered to endosomes containing transferrin receptors. J. Cell Biol. 1993, 123, 89-97. [CrossRef]

39. Larkin, J.M.; Brown, M.S.; Goldstein, J.L.; Anderson, R.G. Depletion of intracellular potassium arrests coated pit formation and receptor-mediated endocytosis in fibroblasts. Cell 1983, 33, 273-285. [CrossRef]

40. Wang, L.H.; Rothberg, K.G.; Anderson, R.G. Mis-assembly of clathrin lattices on endosomes reveals a regulatory switch for coated pit formation. J. Cell Biol. 1993, 123, 1107-1117. [CrossRef]

41. Von Kleist, L.; Stahlschmidt, W.; Bulut, H.; Gromova, K.; Puchkov, D.; Robertson, M.; MacGregor, K.A.; Tomilin, N.; Pechstein, A.; Chau, N.; et al. Role of the Clathrin Terminal Domain in Regulating Coated Pit Dynamics Revealed by Small Molecule Inhibition. Cell 2011, 146, 471-484. [CrossRef]

42. Carpentier, J.-L.; Sawano, F.; Geiger, D.; Gorden, P.; Perrelet, A.; Orci, L. Potassium depletion and hypertonic medium reduce. Non-coated and clathrin-coated pit formation, as well as endocytosis through these two gates. J. Cell Physiol. 1989, 138, 519-526. [CrossRef]

43. Boucrot, E.; Ferreira, A.P.A.; Almeida-Souza, L.; Debard, S.; Vallis, Y.; Howard, G.; Bertot, L.; Sauvonnet, N.; McMahon, H.T. Endophilin marks and controls a clathrin-independent endocytic pathway. Nature 2015, 517, 460-465. [CrossRef] [PubMed]

44. Kilsdonk, E.P.C.; Yancey, P.G.; Stoudt, G.W.; Bangerter, F.W.; Johnson, W.J.; Phillips, M.C.; Rothblat, G.H. Cellular Cholesterol Efflux Mediated by Cyclodextrins. J. Biol. Chem. 1995, 270, 17250-17256. [CrossRef]

45. Bolard, J. How Do the Polyene Macrolide Antibiotics Affect the Cellular Membrane Properties? BBA Rev. Biomembr. 1986, 864, 257-304. [CrossRef]

46. Hao, M.; Mukherjee, S.; Sun, Y.; Maxfield, F.R. Effects of Cholesterol Depletion and Increased Lipid Unsaturation on the Properties of Endocytic Membranes. J. Biol. Chem. 2004, 279, 14171-14178. [CrossRef]

47. Gilleron, J.; Querbes, W.; Zeigerer, A.; Borodovsky, A.; Marsico, G.; Schubert, U.; Manygoats, K.; Seifert, S.; Andree, C.; Stöter, M.; et al. Image-based analysis of lipid nanoparticle-mediated siRNA delivery, intracellular trafficking, and endosomal escape. Nat. Biotechnol. 2013, 31, 638-646. [CrossRef]

48. Lajoie, P.; Nabi, I. Regulation of raft-dependent endocytosis. J. Cell Mol. Med. 2007, 11, 644-653. [CrossRef]

49. Chen, X.; Shank, S.; Davis, P.B.; Ziady, A.G. Nucleolin-Mediated Cellular Trafficking of DNA Nanoparticle Is Lipid Raft and Microtubule Dependent and Can Be Modulated by Glucocorticoid. Mol. Ther. 2011, 19, 93-102. [CrossRef]

50. Foerg, C.; Ziegler, U.; Fernandez-Carneado, J.; Giralt, E.; Rennert, R.; Beck-Sickinger, A.A.G.; Merkle, H.P. Decoding the Entry of Two Novel Cell-Penetrating Peptides in HeLa Cells: Lipid Raft-Mediated Endocytosis and Endosomal Escape. Biochemistry 2005, 44, 72-81. [CrossRef] 
51. Martínez-Riaño, A.; Bovolenta, E.R.; Mendoza, P.; Oeste, C.L.; Martín-Bermejo, M.J.; Bovolenta, P.; Turner, M.; Martínez-Martín, N.; Alarcón, B. Antigen phagocytosis by B cells is required for a potent humoral response. EMBO Rep. 2018, 19, e46016. [CrossRef]

52. Chen, F.; Wang, G.; Griffin, J.I.; Brenneman, B.; Banda, N.K.; Backos, D.S.; Wu, L.; Moghimi, S.M. Complement proteins bind to nanoparticle protein corona and undergo dynamic exchange in vivo. Nat. Nanotechnol. 2016, 12, 387-393. [CrossRef] [PubMed]

53. Sahay, G.; Alakhova, D.Y.; Kabanov, A.V. Endocytosis of Nanomedicines. J. Control. Release 2010, 145, 182-195. [CrossRef] [PubMed]

54. Lazarovits, J.; Chen, Y.Y.; Sykes, E.A.; Chan, W.C.W. Nanoparticle-blood interactions: The implications on solid tumour targeting Chem. Commun. 2014, 51, 2756-2767. [CrossRef]

55. Zhang, Y.-N.; Poon, W.; Tavares, A.J.; McGilvray, I.D.; Chan, W.C.W. Nanoparticle-liver interactions: Cellular uptake and hepatobiliary elimination. J. Control. Release 2016, 240, 332-348. [CrossRef]

56. Tsoi, K.M.; MacParland, S.; Ma, X.-Z.; Spetzler, V.N.; Echeverri, J.; Ouyang, B.; Fadel, S.M.; Sykes, E.A.; Goldaracena, N.; Kaths, J.M.; et al. Mechanism of hard-nanomaterial clearance by the liver. Nat. Mater. 2016, 15, 1212-1221. [CrossRef]

57. Walkey, C.D.; Olsen, J.B.; Guo, H.; Emili, A.; Chan, W.C.W. Nanoparticle Size and Surface Chemistry Determine Serum Protein Adsorption and Macrophage Uptake. J. Am. Chem. Soc. 2012, 134, 2139-2147. [CrossRef]

58. Dai, Q.; Walkey, C.; Chan, W.C.W. Polyethylene Glycol Backfilling Mitigates the Negative Impact of the Protein Corona on Nanoparticle Cell Targeting. Angew. Chem. Int. Ed. 2014, 53, 5093-5096. [CrossRef]

59. Li, Y.; Kröger, M.; Liu, W.K. Endocytosis of PEGylated nanoparticles accompanied by structural and free energy changes of the grafted polyethylene glycol. Biomaterials 2014, 35, 8467-8478. [CrossRef]

60. Ichihara, M.; Shimizu, T.; Imoto, A.; Hashiguchi, Y.; Uehara, Y.; Ishida, T.; Kiwada, H. Anti-PEG IgM Response against PEGylated Liposomes in Mice and Rats. Pharmaceutics 2010, 3, 1-11. [CrossRef]

61. Shah, S.; Prematta, T.; Adkinson, N.F.; Ishmael, F.T. Hypersensitivity to Polyethylene Glycols. J. Clin. Pharmacol. 2013, 53, 352-355. [CrossRef]

62. Kerr, M.C.; Teasdale, R.D. Defining Macropinocytosis. Traffic 2009, 10, 364-371. [CrossRef]

63. Conner, S.D.; Schmid, S. Regulated portals of entry into the cell. Nature 2003, 422, 37-44. [CrossRef]

64. Mercer, J.; Helenius, A. Virus entry by micropinocytosis. Nat. Cell Biol. 2009, 11, 510-520. [CrossRef]

65. Falcone, S.; Cocucci, E.; Podini, P.; Kirchhausen, T.; Clementi, E.; Meldolesi, J. Macropinocytosis: Regulated coordination of endocytic and exocytic membrane traffic events. J. Cell Sci. 2006, 119, 4758-4769. [CrossRef]

66. Wadia, J.S.; Stan, R.V.; Dowdy, S.F. Transducible TAT-HA fusogenic peptide enhances escape of TAT-fusion proteins after lipid raft micropinocytosis. Nat. Med. 2004, 10, 310-315. [CrossRef]

67. Love, K.T.; Mahon, K.P.; Levins, C.G.; Whitehead, K.A.; Querbes, W.; Dorkin, J.R.; Qin, J.; Cantley, W.; Qin, L.L.; Racie, T.; et al. Lipid-like materials for low-dose, in vivo gene silencing. Proc. Natl. Acad. Sci. USA 2010, 107, 1864-1869. [CrossRef]

68. Hallab, N.J.; Bundy, K.J.; O'Connor, K.; Clark, R.; Moses, R.L. Cell adhesion to biomaterials: Correlations between surface charge, surface roughness, adsorbed protein, and cell morphology. J. Long Term Eff. Med. Implant. 1995, 5, $209-231$.

69. Urbančič, I.; Garvas, M.; Kokot, H.; Majaron, H.; Umek, P.; Cassidy, H.; Škarabot, M.; Schneider, F.; Galiani, S.; Arsov, Z.; et al. Nanoparticles Can Wrap Epithelial Cell Membranes and Relocate Them Across the Epithelial Cell Layer. Nano. Lett. 2018, 18, 5294-5305. [CrossRef]

70. Yue, T.; Wang, X.; Huang, F.; Zhang, X. An unusual pathway for the membrane wrapping of rodlike nanoparticles and the orientation- and membrane wrapping-dependent nanoparticle interaction. Nanoscale 2013, 5, 9888-9896. [CrossRef]

71. Zhao, Y.; Wang, Y.; Ran, F.; Cui, Y.; Liu, C.; Zhao, Q.; Gao, Y.; Wang, D.; Wang, S. A comparison between sphere and rod nanoparticles regarding their in vivo biological behavior and pharmacokinetics. Sci. Rep. 2017, 7, 1-11. [CrossRef]

72. Liu, X.; Wu, F.; Tian, Y.; Wu, M.; Zhou, Q.; Jiang, S.; Niu, Z. Size Dependent Cellular Uptake of Rod-like Bionanoparticles with Different Aspect Ratios. Sci. Rep. 2016, 6, 24567. [CrossRef] [PubMed]

73. Qiu, Y.; Liu, Y.; Wang, L.; Xu, L.; Bai, R.; Ji, Y.; Wu, X.; Zhao, Y.; Li, Y.-F.; Chen, C. Surface chemistry and aspect ratio mediated cellular uptake of Au nanorods. Biomaterials 2010, 31, 7606-7619. [CrossRef] [PubMed]

74. Meng, H.; Yang, S.; Li, Z.; Xia, T.; Chen, J.; Ji, Z.; Zhang, H.; Wang, X.; Lin, S.; Huang, C.; et al. Aspect Ratio Determines the Quantity of Mesoporous Silica Nanoparticle Uptake by a Small GTPase-Dependent Macropinocytosis Mechanism. ACS Nano. 2011, 5, 4434-4447. [CrossRef]

75. Gratton, S.E.A.; Ropp, P.A.; Pohlhaus, P.D.; Luft, J.C.; Madden, V.J.; Napier, M.E.; DeSimone, J.M. The effect of particle design on cellular internalization pathways. Proc. Natl. Acad. Sci. USA 2008, 105, 11613-11618. [CrossRef]

76. Shimoni, O.; Yan, Y.; Wang, Y.; Caruso, F. Shape-Dependent Cellular Processing of Polyelectrolyte Capsules. ACS Nano. 2012, 7, 522-530. [CrossRef] [PubMed]

77. Zhao, J.; Stenzel, M.H. Entry of nanoparticles into cells: The importance of nanoparticle properties. Polym. Chem. 2018, 9, 259-272. [CrossRef]

78. Kaga, S.; Truong, N.P.; Esser, L.; Senyschyn, D.; Sanyal, A.; Sanyal, R.; Quinn, J.F.; Davis, T.P.; Kaminskas, L.M.; Whittaker, M.R. Influence of Size and Shape on the Biodistribution of Nanoparticles Prepared by Polymerization-Induced Self-Assembly. Biomacromolecules 2017, 18, 3963-3970. [CrossRef]

79. Arnida; Malugin, A.; Ghandehari, H. Cellular uptake and toxicity of gold nanoparticles in prostate cancer cells: A comparative study of rods and spheres. J. Appl. Toxicol. 2009, 30, 212-217. [CrossRef] 
80. Zhang, P.; Li, B.; Du, J.; Wang, Y. Regulation the morphology of cationized gold nanoparticles for effective gene delivery. Colloids Surf. B Biointerfaces 2017, 157, 18-25. [CrossRef]

81. Kolhar, P.; Anselmo, A.; Gupta, V.; Pant, K.; Prabhakarpandian, B.; Ruoslahti, E.; Mitragotri, S. Using shape effects to target antibody-coated nanoparticles to lung and brain endothelium. Proc. Natl. Acad. Sci. USA 2013, 110, 10753-10758. [CrossRef]

82. Black, K.C.L.; Wang, Y.; Luehmann, H.P.; Cai, X.; Xing, W.; Pang, B.; Zhao, Y.; Cutler, C.S.; Wang, L.V.; Liu, Y.; et al. Radioactive 198Au-Doped Nanostructures with Different Shapes for In Vivo Analyses of Their Biodistribution, Tumor Uptake, and Intratumoral Distribution. ACS Nano. 2014, 8, 4385-4394. [CrossRef] [PubMed]

83. Salatin, S.; Dizaj, S.M.; Khosroushahi, A.Y. Effect of the surface modification, size, and shape on cellular uptake of nanoparticles. Cell Biol. Int. 2015, 39, 881-890. [CrossRef] [PubMed]

84. Ahmad, J.; Wen, X.; Li, F.; Wang, B. Novel triangular silver nanoparticle modified membranes for enhanced antifouling performance. RSC Adv. 2019, 9, 6733-6744. [CrossRef]

85. Nambara, K.; Niikura, K.; Mitomo, H.; Ninomiya, T.; Takeuchi, C.; Wei, J.; Matsuo, Y.; Ijiro, K. Reverse Size Dependences of the Cellular Uptake of Triangular and Spherical Gold Nanoparticles. Langmuir 2016, 32, 12559-12567. [CrossRef] [PubMed]

86. Chithrani, D.; Chan, W.C.W. Elucidating the Mechanism of Cellular Uptake and Removal of Protein-Coated Gold Nanoparticles of Different Sizes and Shapes. Nano. Lett. 2007, 7, 1542-1550. [CrossRef]

87. Nativo, P.; Prior, I.; Brust, M. Uptake and Intracellular Fate of Surface-Modified Gold Nanoparticles. ACS Nano 2008, 2, 1639-1644. [CrossRef]

88. Cho, E.C.; Zhang, Q.; Xia, Y. The effect of sedimentation and diffusion on cellular uptake of gold nanoparticles. Nat. Nanotechnol. 2011, 6, 385-391. [CrossRef]

89. Wong, A.C.; Wright, D.W. Size-Dependent Cellular Uptake of DNA Functionalized Gold Nanoparticles. Small 2016, 12, 5592-5600. [CrossRef]

90. Fabris, L. Gold Nanostars in Biology and Medicine: Understanding Physicochemical Properties to Broaden Applicability. J. Phys. Chem. C 2020, 124, 26540-26553. [CrossRef]

91. Yue, J.; Feliciano, T.J.; Li, W.; Lee, A.; Odom, T.W. Gold Nanoparticle Size and Shape Effects on Cellular Uptake and Intracellular Distribution of siRNA Nanoconstructs. Bioconjugate Chem. 2017, 28, 1791-1800. [CrossRef]

92. Choi, C.H.J.; Hao, L.; Narayan, S.P.; Auyeung, E.; Mirkin, C.A. Mechanism for the endocytosis of spherical nucleic acid nanoparticle conjugates. Proc. Natl. Acad. Sci. USA 2013, 110, 7625-7630. [CrossRef]

93. Xiao, W.; Gao, H. The impact of protein corona on the behavior and targeting capability of nanoparticle-based delivery system Int. J. Pharm. 2018, 552, 328-339. [CrossRef]

94. Ma, N.; Wu, F.-G.; Zhang, X.; Jiang, Y.-W.; Jia, H.-R.; Wang, H.-Y.; Li, Y.-H.; Liu, P.; Gu, N.; Chen, Z. Shape-Dependent Radiosensitization Effect of Gold Nanostructures in Cancer Radiotherapy: Comparison of Gold Nanoparticles, Nanospikes, and Nanorods. ACS Appl. Mater. Interfaces 2017, 9, 13037-13048. [CrossRef]

95. Wang, J.; Chen, H.-J.; Hang, T.; Yu, Y.; Liu, G.; He, G.; Xiao, S.; Yang, B.-R.; Yang, C.; Liu, F.; et al. Physical activation of innate immunity by spiky particles. Nat. Nanotechnol. 2018, 13, 1078-1086. [CrossRef]

96. Arvizo, R.R.; Miranda, O.R.; Thompson, M.A.; Pabelick, C.M.; Bhattacharya, R.; Robertson, J.; Rotello, V.M.; Prakash, Y.S.; Mukherjee, P. Effect of Nanoparticle Surface Charge at the Plasma Membrane and Beyond. Nano. Lett. 2010, 10, 2543-2548. [CrossRef]

97. Zhang, D.; Wei, L.; Zhong, M.; Xiao, L.; Li, H.-W.; Wang, J. The morphology and surface charge-dependent cellular uptake efficiency of upconversion nanostructures revealed by single-particle optical microscopy. Chem. Sci. 2018, 9, 5260-5269. [CrossRef]

98. He, C.; Hu, Y.; Yin, L.; Tang, C.; Yin, C. Effects of particle size and surface charge on cellular uptake and biodistribution of polymeric nanoparticles. Biomaterials 2010, 31, 3657-3666. [CrossRef]

99. Jeon, S.; Clavadetscher, J.; Lee, D.-K.; Chankeshwara, S.V.; Bradley, M.; Cho, W.-S. Surface Charge-Dependent Cellular Uptake of Polystyrene Nanoparticles. Nanomaterials 2018, 8, 1028. [CrossRef]

100. Song, Y.-Y.; Lu, Y. Decision tree methods: Applications for classification and prediction. Shanghai Arch. Psychiatry 2015, 27, 130-135. [CrossRef]

101. Basant, N.; Gupta, S. Modeling uptake of nanoparticles in multiple human cells using structure-Activity relationships and intercellular uptake correlations. Nanotoxicology 2016, 11, 20-30. [CrossRef]

102. Chau, Y.T.; Yap, C.W. Quantitative Nanostructure-Activity Relationship modelling of nanoparticles. RSC Adv. 2012, 2, 8489-8496. [CrossRef]

103. Singh, K.P.; Gupta, S. Nano-QSAR modeling for predicting biological activity of diverse nanomaterials. RSC Adv. 2014, 4, 13215-13230. [CrossRef]

104. Papa, E.; Doucet, J.P.; Doucet-Panaye, A. Computational approaches for the prediction of the selective uptake of magnetofluorescent nanoparticles into human cells. RSC Adv. 2016, 6, 68806-68818. [CrossRef]

105. Helfrich, W. Elastic Properties of Lipid Bilayers: Theory and Possible Experiments. Z. Nat. C 1973, 28, 693-703. [CrossRef] [PubMed]

106. Shen, Z.; Ye, H.; Li, Y. Understanding receptor-mediated endocytosis of elastic nanoparticles through coarse grained molecular dynamic simulation. Phys. Chem. Chem. Phys. 2018, 20, 16372-16385. [CrossRef] [PubMed]

107. Bradley, R.; Radhakrishnan, R. Coarse-Grained Models for Protein-Cell Membrane Interactions. Polymers 2013, 5, 890-936. [CrossRef] [PubMed] 
108. Marrink, S.J.; Corradi, V.; Souza, P.C.T.; Ingólfsson, H.I.; Tieleman, D.P.; Sansom, M.S.P. Computational Modeling of Re-alistic Cell Membranes. Chem. Rev. 2019, 119, 6184-6226. [CrossRef] [PubMed]

109. Monticelli, L.; Kandasamy, S.K.; Periole, X.; Larson, R.G.; Tieleman, D.P.; Marrink, S. The MARTINI Coarse-Grained Force Field: Extension to Proteins. J. Chem. Theory Comput. 2008, 4, 819-834. [CrossRef]

110. López, C.A.; Rzepiela, A.; De Vries, A.H.; Dijkhuizen, L.; Hünenberger, P.; Marrink, S. Martini Coarse-Grained Force Field: Extension to Carbohydrates. J. Chem. Theory Comput. 2009, 5, 3195-3210. [CrossRef]

111. Uusitalo, J.J.; Ingólfsson, H.I.; Akhshi, P.; Tieleman, D.P.; Marrink, S.J. Martini Coarse-Grained Force Field: Extension to DNA. J. Chem. Theory Comput. 2015, 11, 3932-3945. [CrossRef]

112. Lee, H.; de Vries, A.H.; Marrink, S.; Pastor, R.W. A Coarse-Grained Model for Polyethylene Oxide and Polyethylene Glycol: Conformation and Hydrodynamics. J. Phys. Chem. B 2009, 113, 13186-13194. [CrossRef]

113. Wong-Ekkabut, J.; Baoukina, S.; Triampo, W.; Tang, I.-M.; Tieleman, D.P.; Monticelli, L. Computer simulation study of fullerene translocation through lipid membranes. Nat. Nanotechnol. 2008, 3, 363-368. [CrossRef]

114. Lunnoo, T.; Assawakhajornsak, J.; Puangmali, T. In Silico Study of Gold Nanoparticle Uptake into a Mammalian Cell: Interplay of Size, Shape, Surface Charge, and Aggregation. J. Phys. Chem. C 2019, 123, 3801-3810. [CrossRef]

115. Casalini, T.; Limongelli, V.; Schmutz, M.; Som, C.; Jordan, O.; Wick, P.; Borchard, G.; Perale, G. Molecular Modeling for Nanomaterial-Biology Interactions: Opportunities, Challenges, and Perspectives. Front. Bioeng. Biotechnol. 2019, 7, 268. [CrossRef]

116. Liu, M.B.; Liu, G.R.; Zhou, L.W.; Chang, J.Z. Dissipative Particle Dynamics (DPD): An Overview and Recent Developments. Arch. Comput. Methods Eng. 2014, 22, 529-556. [CrossRef]

117. Yang, K.; Ma, Y.-Q. Computer simulation of the translocation of nanoparticles with different shapes across a lipid bilayer. Nat. Nanotechnol. 2010, 5, 579-583. [CrossRef]

118. Zhang, X.; Ma, G.; Wei, W. Simulation of nanoparticles interacting with a cell membrane: Probing the structural basis and potential biomedical application. NPG Asia Mater. 2021, 13, 1-18. [CrossRef]

119. Heikkilä, E.; Martinez-Seara, H.; Gurtovenko, A.A.; Vattulainen, I.; Akola, J. Atomistic simulations of anionic Au144(SR)60 nanoparticles interacting with asymmetric model lipid membranes. Biochim. Biophys. Acta Biomembr. 2014, 1838, 2852-2860. [CrossRef]

120. Petelska, A.D.; Figaszewski, Z.A. Interfacial tension of bilayer lipid membrane formed from phosphatidylethanolamine. Biochim. Biophys. Acta Biomembr. 2002, 1567, 79-86. [CrossRef]

121. Ebong, E.; Kumar, R.; Sridhar, S.; Webster, T.J.; Cheng, M.J. Endothelial glycocalyx conditions influence nanoparticle uptake for passive targeting. Int. J. Nanomed. 2016, 11, 3305-3315. [CrossRef] 